\title{
Orthotropic Models of Corrugated Sheets in Finite Element Analysis
}

\author{
David Wennberg, Per Wennhage, and Sebastian Stichel \\ Department of Aeronautical and Vehicle Engineering, The Royal Institute of Technology (KTH), Teknikringen 8, \\ 10044 Stockholm, Sweden \\ Correspondence should be addressed to David Wennberg, davidwen@kth.se
}

Received 28 January 2011; Accepted 21 March 2011

Academic Editors: F. Findik and A. Tounsi

Copyright ( $\odot 2011$ David Wennberg et al. This is an open access article distributed under the Creative Commons Attribution License, which permits unrestricted use, distribution, and reproduction in any medium, provided the original work is properly cited.

To reduce computational effort of finite element (FE) calculations a corrugated sheet is replaced with an orthotropic plate. Analytical expressions for the mechanical properties are studied and compared to finite Element calculations in extension, free vibration, and buckling. Good similarity is shown in the stiffened and transverse direction of the corrugated sheet; however, the orthotropic models do not give an accurate twisting behavior. The stiffened direction of the corrugated sheet best matches the analytical expressions. Keeping in mind the presented limitation, the orthotropic model presented herein can be used to drastically reduce the number of elements needed when modelling corrugated sheet with finite elements.

\section{Introduction}

Modeling corrugated sheets using the finite element method (FEM) usually requires an extensive amount of elements. To reduce the required amount of elements, 2-dimensional, orthotropic models may be used to represent the properties of a corrugated sheet. Samanta and Mukhopadhyay [1], Briassoulis [2], and Liew et al. [3] have derived analytical expressions for the extensional and flexural rigidities of a corrugated sheet. These expressions are here benchmarked against each other with finite element analysis (FEA) in extension, modal analysis, checking both frequency and mode shape, and buckling analysis. Furthermore, a 3-dimensional corrugated sheet model is used as a reference.

The specific construction studied in this paper is the structural floor of a rail vehicle. It is designed of corrugated sheet metal and a metal framework as the load carrying structure. To reduce computational effort, and enable fast parameter studies of the entire rail car, the original FE model has to be reduced.

Another goal of this exercise is to find a more efficient substitution to the existing structure (efficient here meaning lighter with the same mechanical properties). A possible competitor to the corrugated sheet and frame construction may be a sandwich panel structure. The expressions tested and formulated in this paper may, as well as simplifying FE modeling, also be used as design parameters in a sandwichpanel material and geometry selection process.

In this paper, parameters without subindices are the regular, isotropic parameters for the material in question. Sub-indexed parameters refer to the orthotropic model, and indices are with respect to directions illustrated in Figure 1.

\section{Method}

The corrugated sheet was studied in free vibration, extension, and buckling. FE calculations were performed with the software package HyperWorks, where HyperMesh was used as a preprocessor, RADIOSS as the solver, and HyperView as the postprocessor. To create an orthotropic equivalent of the corrugated sheet in HyperMesh, the PSHELL element property was used and the MID1 (membrane) and MID2 (bending) material options in the PSHELL properties were activated [4]. Material properties for MID1 and MID2 were 


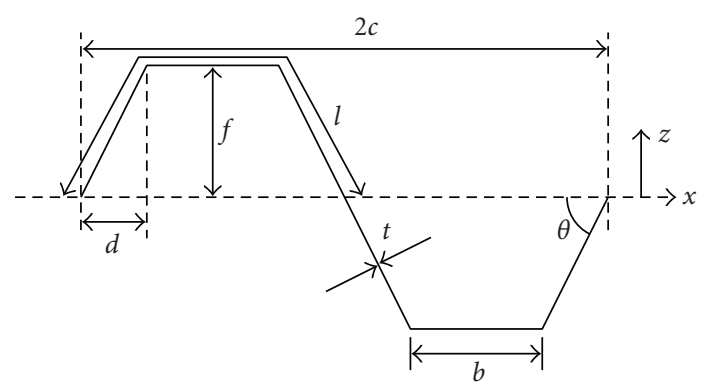

FIguRE 1: Cross-section of one repeated corrugation of a larger corrugated sheet.

defined by the MAT2 constitutive material matrix presented below,

$$
\left(\begin{array}{c}
\sigma_{1} \\
\sigma_{2} \\
\tau_{12}
\end{array}\right)=\left[\begin{array}{lll}
G_{11} & G_{12} & G_{13} \\
G_{21} & G_{22} & G_{23} \\
G_{31} & G_{32} & G_{33}
\end{array}\right]\left(\begin{array}{c}
\epsilon_{1} \\
\epsilon_{2} \\
\gamma_{12}
\end{array}\right)
$$

For each orthotropic model, two such constitutive matrices are thus calculated, one for bending and one for the membrane properties of the corrugated sheet.

The comparison of free vibration properties was performed using four FE models of a large, unsupported sheet. One model was a thorough, 3-dimensional representation of the corrugated sheet, and the other three models were of orthotropic plates with equivalent flexural rigidities calculated according to Samanta and Mukhopadhyay [1], Briassoulis [2], and Liew et al. [3], see Figure 2. These rigidities were used to calculate the input for the MID2 material properties defined above. Both the natural frequencies and the mode shapes were compared between the different models.

Extensional rigidities were calculated according to Samanta and Mukhopadhyay [1] and Briassoulis [2]. These values were benchmarked in extension, again with a fully modeled corrugated sheet as a reference.

For the comparison of buckling behavior, four models were created, cf. Figure 3. Model B:1 is a supported corrugated sheet which was loaded along two edges. Buckling loads for this model were calculated by means of finite element analysis (FEA). Model B:2 is an equivalent orthotropic plate of the same size as B:1, loaded and constrained in the same way. Model B:3, which illustrates a representative part of a corrugation, was also modeled with FE and compared to analytical Euler buckling loads and local buckling loads calculated from Model B:4. Material properties for the orthotropic plate model were chosen as the material properties that best matched the fully corrugated model from the previous two tests in free vibration and extension.

An overview of the analyses performed can be found in Table 1.

2.1. Orthotropic Plates. Assuming we have large corrugated sheets, that is, the corrugation size is small in comparison to the overall size of the sheet, we may be able to model the sheet
TABLe 1: Summary of the different analyses performed, cf. Figures 2 and 3 .

\begin{tabular}{lll}
\hline Analysis & Models & Properties from \\
\hline & $\begin{array}{l}\text { 3D FE corrugated } \\
\text { sheet }\end{array}$ & - \\
Free vibration (1) & Orthotropic FE plate & $\begin{array}{l}\text { Samanta and } \\
\text { Mukhopadhyay }\end{array}$ \\
& $\begin{array}{l}\text { Orthotropic FE plate } \\
\text { Orthotropic FE plate }\end{array}$ & Briassoulis \\
& Liew et al. \\
\hline & sheet corrugated & - \\
Extensional (2) & Orthotropic FE plate & Samanta and \\
& Orthotropic FE plate & Briassoulis \\
\hline & $\begin{array}{l}\text { 3D FE corrugated } \\
\text { sheet }\end{array}$ & - \\
& 3D FE beam & - \\
& Orthotropic FE plate & Best result from (1) \\
& and (2) \\
& Analytical column & - \\
\hline
\end{tabular}

as a thin orthotropic plate with the stress-strain relationship as follows:

$$
\left(\begin{array}{c}
\sigma_{x} \\
\sigma_{y} \\
\tau_{x y}
\end{array}\right)=\frac{1}{1-v_{x y} \nu_{y x}}\left[\begin{array}{ccc}
E_{x} & \nu_{y x} E_{x} & 0 \\
\nu_{x y} E_{y} & E_{y} & 0 \\
0 & 0 & \left(1-\nu_{x y} \nu_{y x}\right) G_{x y}
\end{array}\right]\left(\begin{array}{c}
\epsilon_{x} \\
\epsilon_{y} \\
\gamma_{x y}
\end{array}\right)
$$

For an arbitrary orthotropic, thin plate, the flexural rigidities may be expressed as

$$
\begin{gathered}
D_{x}=\frac{E_{x} t^{3}}{12\left(1-v_{x y} \nu_{y x}\right)}, \\
D_{y}=\frac{E_{y} t^{3}}{12\left(1-v_{x y} \nu_{y x}\right)}, \\
D_{x y}=\frac{G_{x y} t^{3}}{6} .
\end{gathered}
$$

Furthermore, for a corrugated sheet, the Poisson's ratio $v_{y x}$, is the same as that of the isotropic material [2], that is, $v_{y x}=\nu$. To find $v_{x y}$, we utilise the relation [3]

$$
\frac{v_{x y}}{v_{y x}}=\frac{E_{x}}{E_{y}}=\frac{D_{x}}{D_{y}} .
$$

Rearranging (4) gives

$$
v_{x y}=\frac{D_{x}}{D_{y}} \nu_{y x}=\frac{D_{x}}{D_{y}} \nu .
$$




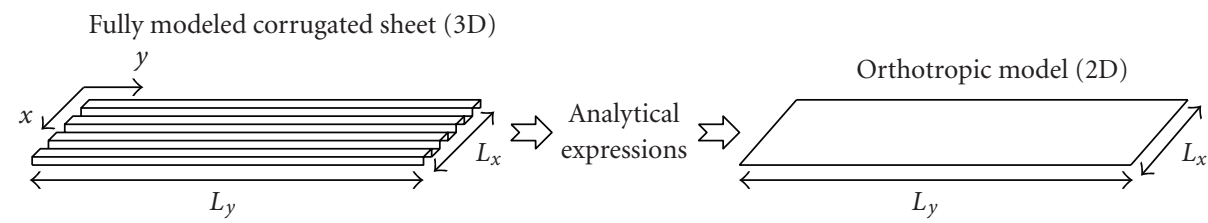

Figure 2: Models used in modal analysis and extensional test. Geometric parameters from the corrugated sheet are used in analytical expressions to calculate equivalent orthotropic properties for the 2D orthotropic plate.
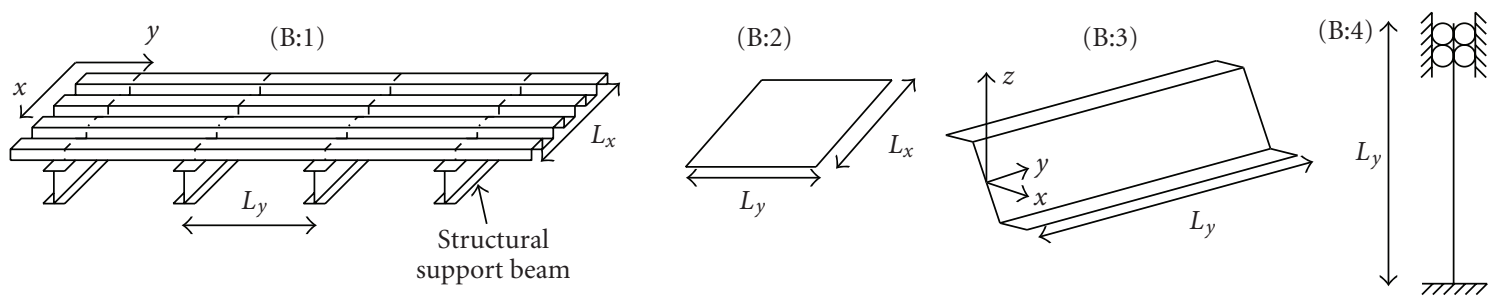

Figure 3: Models used in buckling analysis. In B:1 it is the section $L_{x}$ by $L_{y}$ which is studied in buckling, not the entire structure. Geometric parameters from B:1 are used in analytical expressions to calculate equivalent orthotropic properties for B:2. B:3 is a representative part of $\mathrm{B}: 1$, this model is compared to the analytical result of Euler buckling found in B:4.

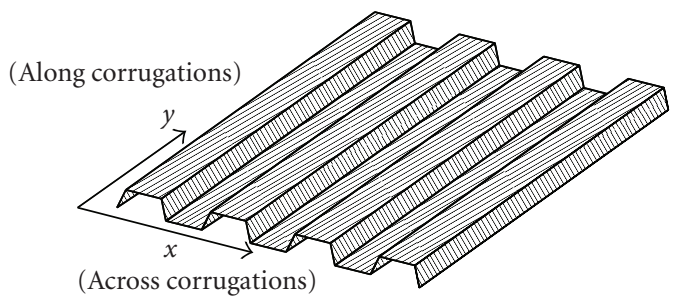

FIgURE 4: Directions in the corrugated sheet.

Utilising (3) to express the Young's modulus as a function of the bending rigidity, we get

$$
\begin{gathered}
E_{x}=\frac{12\left(1-v_{x y} v_{y x}\right)}{t^{3}} D_{x}, \\
E_{y}=\frac{12\left(1-v_{x y} v_{y x}\right)}{t^{3}} D_{y}, \\
G_{x y}=\frac{6 D_{x y}}{t^{3}} .
\end{gathered}
$$

The extensional rigidities and moduli of an orthotropic plate (here denoted $B$ and $E^{e}$ to distinguish from the flexural expressions) follow the relations [2]

$$
\begin{aligned}
B_{x} & =E_{x}^{e} t, \\
B_{y} & =E_{y}^{e} t, \\
B_{x y} & =G_{x y}^{e} t .
\end{aligned}
$$

\section{Corrugated Model}

The model used in this study is $12.164 \mathrm{~m}$ long ( $y$-dir) and $2.336 \mathrm{~m}$ wide $(x$-dir), which is a significant part of a rail vehicle's floor area, see Figure 4 for definition of directions.
TABLE 2: Material data and parameters for the studied corrugated sheet. Parameters can be found in Figure 1.

\begin{tabular}{lc}
\hline Property & Value \\
\hline$E(\mathrm{~Pa})$ & $2.00 E 11$ \\
$c(\mathrm{~m})$ & $3.85 E-2$ \\
$l(\mathrm{~m})$ & $5.45 E-2$ \\
$f(\mathrm{~m})$ & $1.25 E-2$ \\
$\theta(\mathrm{rad})$ & 1.14 \\
$d(\mathrm{~m})$ & $5.75 E-3$ \\
$b(\mathrm{~m})$ & $2.70 E-2$ \\
$t(\mathrm{~m})$ & $1.50 E-3$ \\
$\nu(-)$ & $3.00 E-1$ \\
$I_{y}\left(\mathrm{~m}^{4}\right)$ & $8.49 E-9$ \\
\hline
\end{tabular}

The model weight is $475.1 \mathrm{~kg}$. Remaining properties can be found in Table 2.

The density used in the orthotropic models was estimated as $(l / c) \rho$, where $\rho$ is the density of steel. The thickness of the orthotropic plate is equal to that of the corrugated sheet, $t$.

\section{Flexural Properties}

To derive the expressions for the flexural moduli, Liew et al. [3] used the following expressions for the flexural rigidities:

$$
\begin{gathered}
D_{x}=\frac{E t^{3}}{12\left(1-v^{2}\right)} \frac{c}{l}, \\
D_{y}=\frac{E t^{3}}{12\left(1-v^{2}\right)}+\frac{E t}{c} \alpha, \\
D_{x y}=\frac{E t^{3}}{12(1+v)},
\end{gathered}
$$


where $E$ is the Young's modulus of the material and $v$ is Poisson's ratio; the other parameters, all but $\alpha$, are geometric variables described in Figure 1. The parameter $\alpha$ is given by [3]

$$
\begin{aligned}
\alpha= & \frac{f^{3}}{3 \tan \theta}+f^{2} b+\frac{1}{3} \tan ^{2} \theta\left(c^{3}-\left(b+\frac{f}{\tan \theta}\right)^{3}\right) \\
& -(2 f+b \tan \theta) \tan \theta\left(c^{2}-\left(b+\frac{f}{\tan \theta}\right)^{2}\right) \\
& +(2 f+b \tan \theta)^{2}\left(c-b-\frac{f}{\tan \theta}\right) .
\end{aligned}
$$

Equations (8)-(10) were derived by Briassoulis [2]. Liew et al. have, however, made changes to the calculation of $D_{y}$. Briassoulis original expression for $D_{y}$ is given by

$$
D_{y}=\frac{E t^{3}}{12\left(1-v^{2}\right)}+\frac{E t f^{2}}{2} \text {. }
$$

Briassoulis' equations are modified equations from, for example, Easley [5].

A third variant of the flexural rigidities is given by Samanta and Mukhopadhyay [1]

$$
\begin{gathered}
D_{x}=\frac{c}{l} \frac{E t^{3}}{12}, \\
D_{y}=\frac{E I_{y}}{c}, \\
D_{x y}=\frac{l}{c} \frac{E t^{3}}{6(1+v)} .
\end{gathered}
$$

These equations are similar to the ones used by Briassoulis, and, furthermore, Samanta and Mukhopadhyay and Briassoulis have referenced the same original authors [5-7].

The three orthotropic models (Liew's, Samanta's, and Briassoulis') were compared to a 3D model of the corrugated plate in free vibration.

4.1. Flexural Analysis. Bending rigidities calculated with the three methods presented in Section 4 can be found in Table 3. The elasticity moduli corresponding to the bending rigidities found in Table 3 are presented in Table 4. These values were used to calculate the constitutive relation in (1), which was used to describe the orthotropic models' bending characteristics for free vibration analysis.

The first six eigen modes of the reference model, that is, the corrugated model, are depicted in Figure 5.

Results from the modal analysis of the three orthotropic models in comparison to the reference model are found in Table 5.

\section{Extensional Properties}

For extensional rigidities, both Samanta and Mukhopadhyay [1] and Briassoulis [2] have derived similar equations.
TABLE 3: Comparison of flexural rigidities calculated with methods described in Section 1.

\begin{tabular}{lccc}
\hline & $\begin{array}{c}\text { Liew } \\
(\mathrm{Nm})\end{array}$ & $\begin{array}{c}\text { Samanta } \\
(\mathrm{Nm})\end{array}$ & $\begin{array}{c}\text { Briassoulis } \\
(\mathrm{Nm})\end{array}$ \\
\hline$D_{x}$ & $4.37 E 1$ & $3.97 E 1$ & $4.37 E 1$ \\
$D_{y}$ & $3.76 E 4$ & $4.41 E 4$ & $2.35 E 4$ \\
$D_{x y}$ & $4.33 E 1$ & $1.23 E 2$ & $4.33 E 1$ \\
\hline
\end{tabular}

TABLE 4: Orthotropic moduli calculated with (6) and bending rigidities found in Table 3 .

\begin{tabular}{lccc}
\hline & $\begin{array}{c}\text { Liew } \\
(\mathrm{Pa})\end{array}$ & $\begin{array}{c}\text { Samanta } \\
(\mathrm{Pa})\end{array}$ & $\begin{array}{c}\text { Briassoulis } \\
(\mathrm{Pa})\end{array}$ \\
\hline$E_{x}$ & $1.55 E 11$ & $1.41 E 11$ & $1.55 E 11$ \\
$E_{y}$ & $1.34 E 14$ & $1.57 E 14$ & $8.35 E 13$ \\
$G_{x y}$ & $7.69 E 10$ & $2.18 E 11$ & $7.69 E 10$ \\
\hline
\end{tabular}

Samanta and Mukhopadhyay have presented the following expression:

$$
\begin{gathered}
B_{x}=\frac{E(t / f)^{2} t}{6[(2 / c)((c-l \cos \theta) /(1-\cos \theta))+(4 f / 3 c \sin \theta)]}, \\
B_{y}=E t \frac{l}{c}, \\
B_{x y}=\frac{c}{l} \frac{E t}{2(1+v)}
\end{gathered}
$$

while Briassoulis has derived different versions of $B_{x}$ and $B_{x y}$ (see below)

$$
\begin{gathered}
B_{x}=\frac{E t}{1+(f / t)^{2} 6\left(1-v^{2}\right)\left(l^{2} / c^{2}-(l / 2 \pi c) \sin (2 \pi l / c)\right)}, \\
B_{y}=E t \frac{l}{c}, \\
B_{x y}=\frac{E t}{2(1+v)} .
\end{gathered}
$$

An extensional benchmark calculation between a fully modeled corrugated metal sheet and orthotropic equivalents with values according to Briassoulis and Samanta and Mukhopadhyay was performed with FEA. A tensional load of $10 \mathrm{kN}$ was applied along each side of the sheets, separately, in two calculations. The models, the orthotropic and corrugated, are oriented as shown in Figure 4, that is, $y$ is along the corrugations and $x$ is across. The loading condition is depicted in Figure 6.

5.1. Extensional Loading. Extensional moduli for the methods presented by Samanta and Mukhopadhyay [1] and Briassoulis [2], cf. Section 5, are presented in Table 6.

The results from the FE extensional benchmark comparison between the method presented by Briassoulis, Samanta, and the corrugated reference can be found in Table 7 . 


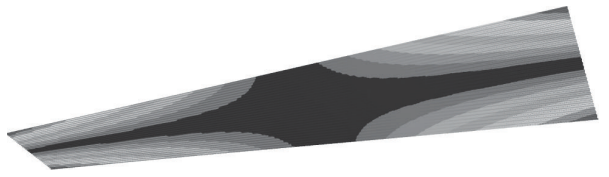

(a) First eigen mode of original model, $0.18 \mathrm{~Hz}$. Eigen mode type a

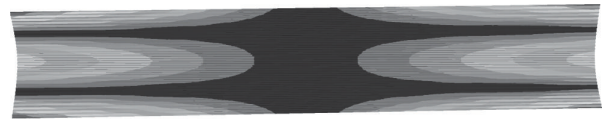

(c) Third eigen mode of original model, $1.12 \mathrm{~Hz}$. Eigen mode type $\mathrm{c}$

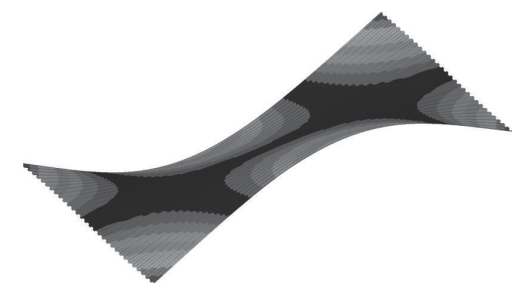

(e) Fifth eigen mode of original model, $1.29 \mathrm{~Hz}$. Eigen mode type e

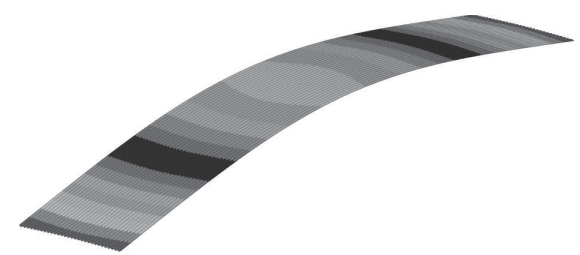

(b) Second eigen mode of original model, $1.06 \mathrm{~Hz}$. Eigen mode type $b$

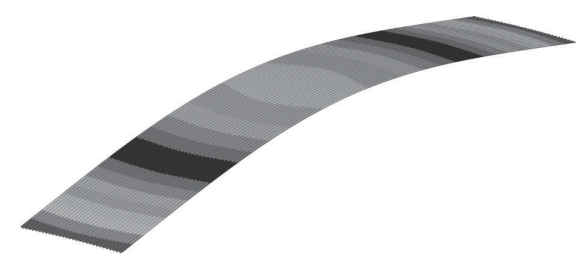

(d) Fourth eigen mode of original model, $1.24 \mathrm{~Hz}$. Eigen mode type d

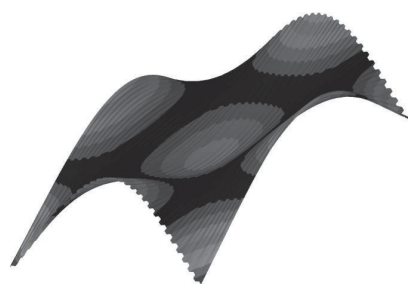

(f) Sixth eigen mode of original model, $1.80 \mathrm{~Hz}$. Eigen mode type f

Figure 5: Modal analysis of corrugated sheet, first six eigen modes.

TABLE 5: Comparison of the first six eigen modes of the orthotropic models and the original model. The different types refer to the type of eigen mode defined in the original model, for example, type $\mathrm{b}$ is the first bending mode around the $x$-axis, cf. Figure 5(b). The reduction of frequency compared to the original model is represented by $\Delta$.

\begin{tabular}{|c|c|c|c|c|c|c|c|}
\hline \multicolumn{2}{|c|}{ Original } & \multicolumn{2}{|c|}{ Liew } & \multicolumn{2}{|c|}{ Samanta } & \multicolumn{2}{|c|}{ Briassoulis } \\
\hline $\begin{array}{l}\text { Type } \\
-\end{array}$ & $\begin{array}{c}\text { Frequency } \\
(\mathrm{Hz})\end{array}$ & $\begin{array}{c}\text { Frequency } \\
\quad(\mathrm{Hz})\end{array}$ & $\begin{array}{c}\Delta \\
(\%)\end{array}$ & $\begin{array}{c}\text { Frequency } \\
(\mathrm{Hz})\end{array}$ & $\begin{array}{c}\Delta \\
(\%)\end{array}$ & $\begin{array}{c}\text { Frequency } \\
\quad(\mathrm{Hz})\end{array}$ & $\begin{array}{c}\Delta \\
(\%)\end{array}$ \\
\hline $\mathrm{a}$ & 0.18 & 0.15 & 16.57 & 0.25 & -38.67 & 0.15 & 17.13 \\
\hline b & 1.06 & 1.03 & 2.83 & 0.98 & 7.26 & 1.03 & 2.83 \\
\hline c & 1.12 & 1.07 & 4.46 & 1.10 & 1.79 & 1.07 & 4.46 \\
\hline d & 1.24 & 1.14 & 8.06 & 1.23 & 0.81 & 0.90 & 27.5 \\
\hline e & 1.29 & 1.17 & 9.30 & 1.32 & -2.33 & 0.94 & 26.82 \\
\hline $\mathrm{f}$ & 1.80 & 1.63 & 9.44 & 1.85 & -2.78 & 1.48 & 17.78 \\
\hline
\end{tabular}

\section{Buckling}

A suitable replacement for the corrugated sheet must also have a sufficient buckling strength. Therefore buckling characteristics of the corrugated sheet and the orthotropic model are studied and compared. Buckling analysis was performed on a part of the corrugated sheet with properties according to Table 2 and dimensions $2271.5\left(L_{x}\right)$ by $746.6\left(L_{y}\right) \mathrm{mm}$. This is equivalent to a part of the corrugated sheet between two support beams in the floor of the studied rail vehicle, cf. Figure 3. The plate was subjected to compression in the corrugated direction, that is, the $y$-direction. Long edges were clamped to simulate a continuous plate attached to the structural beams, and short edges were simply supported, cf. Figure 7.

An orthotropic model was also studied. Here values were chosen as the ones that showed best coherence to the fully corrugated model in the previous two tests, that is, flexural properties according to Samanta and Mukhopadhyay and extensional properties according to Briassoulis.

To derive analytical expressions for the buckling stress, half a corrugation was studied analytically and by means of FE analysis. Modeled with appropriate boundary conditions, a half corrugation will buckle at approximately the same buckling-stress as the entire sheet. Geometry of a half corrugation beam is illustrated in Figure 8. Boundary conditions 


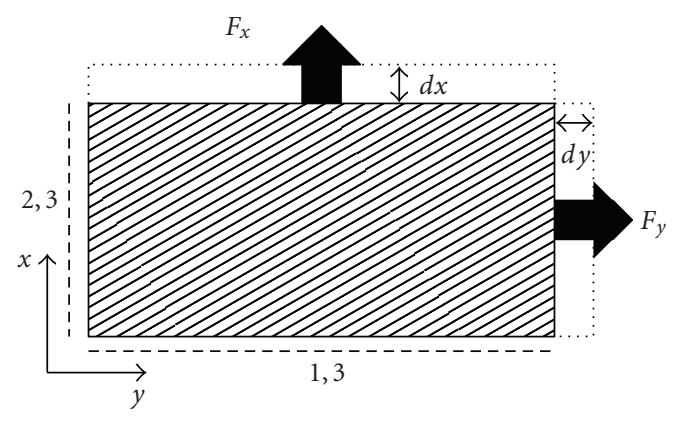

FIGURE 6: Loading and boundary conditions for two extensional benchmark tests of corrugated and orthotropic plate. Dashed lines are simply supported boundary.

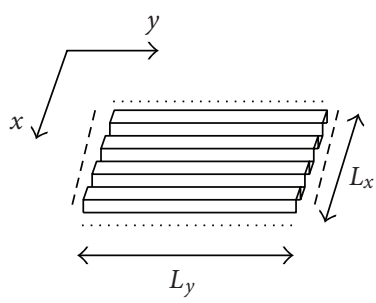

FIGURE 7: Illustration of corrugated section subjected to buckling analysis, see also Figure 3. Dashed lines are clamped and dotted lines are simply supported.

TABLE 6: Extensional moduli comparison between methods found in $[1,2]$.

\begin{tabular}{lcc}
\hline & $\begin{array}{c}\text { Samanta } \\
(\mathrm{Pa})\end{array}$ & $\begin{array}{c}\text { Briassoulis } \\
(\mathrm{Pa})\end{array}$ \\
\hline$E_{x}^{e}$ & $2.55 E 8$ & $2.78 E 8$ \\
$E_{y}^{e}$ & $2.83 E 11$ & $2.83 E 11$ \\
$G_{x y}^{e}$ & $5.43 E 10$ & $7.69 E 10$ \\
\hline
\end{tabular}

TABLE 7: Strain of corrugated sheet and orthotropic models due to $10 \mathrm{kN}$ loading in $x$ and $y$ directions, cf. Figures 6 and 4 .

\begin{tabular}{lccc}
\hline & $\begin{array}{c}\text { Corrugated } \\
\text { sheet }\end{array}$ & Briassoulis & $\begin{array}{c}\text { Samanta and } \\
\text { Mukhopadhyay }\end{array}$ \\
\hline Strain $\epsilon_{y}(-)$ & $1.05 E-5$ & $1.05 E-5$ & $1.05 E-5$ \\
Strain $\epsilon_{x}(-)$ & $4.71 E-3$ & $5.48 E-3$ & $5.97 E-3$ \\
\hline
\end{tabular}

applied during FE analysis can be found in Table 8. Euler buckling and local buckling was calculated analytically. by $[8]$

The analytical buckling load, for Euler buckling, is given

$$
P_{\mathrm{cr}}^{E}=\frac{\pi^{2} E I}{l_{e}^{2}}
$$

where $l_{e}$ is the effective length of the column and is defined as half the length of the column for a case with both edges clamped, cf. Megson, [8, page 258]. I, which in this case
TABLE 8: Boundary conditions for half-corrugation buckling analysis.

\begin{tabular}{lc}
\hline Edge & $\mathrm{BC}$ \\
\hline Long edges & $u=0, d w / d x=0$ \\
Short edges & $u=0, w=0, d w / d y=0$ \\
\hline
\end{tabular}

may be written $I_{x}$, is the second moment of area of the cross section defined as

$$
I_{x}=\int_{C} z^{2} d A
$$

The critical stress is then calculated as

$$
\sigma_{\mathrm{cr} \text { half }}=\frac{P_{\mathrm{cr}}^{E}}{A_{x z, \text { half }}},
$$

where $A_{x z \text {,half }}$ is the cross-section area of the half-corrugation.

The analytical local buckling stress is given by [8]

$$
\sigma_{\mathrm{cr}, \mathrm{local}}=\frac{k \pi^{2} E}{12\left(1-v^{2}\right)}\left(\frac{t}{l_{b}}\right)^{2}=3.6 E\left(\frac{t}{l_{b}}\right)^{2},
$$

where $k$ is the buckling coefficient and $l_{b}$ is the shorter side length of the plate, in this case the loaded side lengths $13.5 \mathrm{~mm}$ and $27.5 \mathrm{~mm}$. For the half corrugation it will be the web that is most critical.

6.1. Buckling Results. The first buckling mode of the small corrugated sheet section situated between structural beams, cf. Figure 7, is shown in Figure 9. Buckling occurred at a total load of about 6.21 MN. The total cross sectional area of this sheet is

$$
A=4823 \mathrm{~mm}^{2} .
$$

This gives a critical stress of

$$
\sigma_{\mathrm{cr}}=\frac{P_{\mathrm{cr}}}{A}=\frac{6.21 \cdot 10^{6}}{4823}=1288 \mathrm{MPa} .
$$

The first buckling mode of the orthotropic plate model corresponded to a load of $7.16 \mathrm{MN}$. Since this model was created with the same sheet thickness as the sheet metal used in the fully corrugated model, that is, $1.5 \mathrm{~mm}$, we get a significantly higher buckling stress (the total cross-section area is a factor $l / c$ smaller)

$$
\sigma_{\mathrm{cr}}=\frac{P_{\mathrm{cr}}}{A}=\frac{7.16 \cdot 10^{6}}{1.5 \cdot 2271.5}=2101 \mathrm{MPa}
$$

Corrected with the factor $l / c$, we get a comparable buckling stress of $1484 \mathrm{MPa}$.

The first critical buckling load of the half corrugation model presented in Section 6 was calculated to $111.8 \mathrm{kN}$; the buckling mode is illustrated in Figure 10.

The area of this cross sections is

$$
A_{x z, \text { half }}=82 \mathrm{~mm}^{2} .
$$



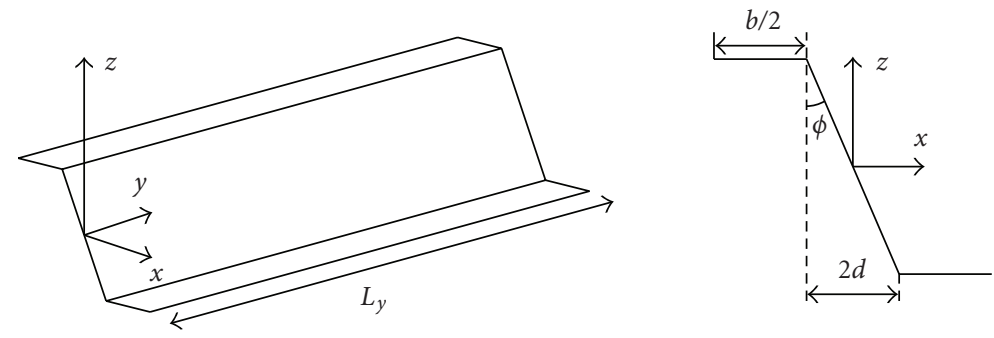

FIGURE 8: Geometry of half a corrugation of the corrugated sheet presented in Figure 1.

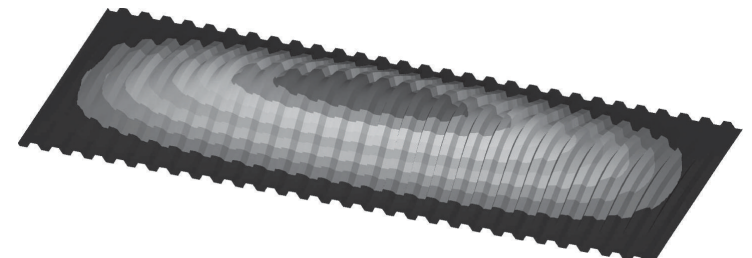

FIGURE 9: First buckling mode of corrugated sheet, critical load 6.21 MN.

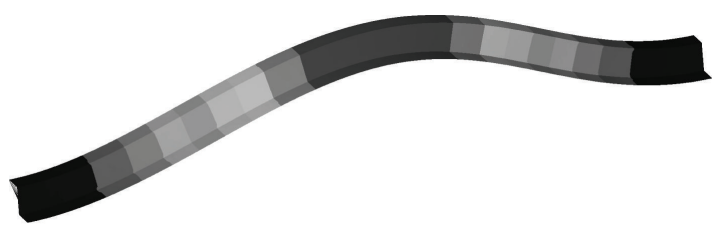

Figure 10: First buckling mode of half corrugation.

This gives us a critical stress of

$$
\sigma_{\mathrm{cr}, \text { half }}=\frac{P_{\mathrm{cr}, \text { half }}}{A_{x z, \text { half }}}=\frac{111.8 \cdot 10^{3}}{82}=1363 \mathrm{MPa} .
$$

The moment of inertia for the half corrugation beam is

$$
I_{x}=8487 \mathrm{~mm}^{4} \text {. }
$$

Furthermore, $E=200 \mathrm{GPa}$, and $l=746.6 \mathrm{~mm}$. This gives an analytical Euler buckling load, according to (18), of

$$
P_{\mathrm{cr}, \text { half }}^{E}=\frac{\pi^{2} \cdot 2.0 \cdot 10^{5} \cdot 8487}{(0.5 \cdot 746.6)^{2}}=120 \mathrm{kN}
$$

The finite element analysis gave a first local buckling mode, for the half corrugation model, at a compressive load of $173 \mathrm{kN}$, which equals a critical stress of $2110 \mathrm{MPa}$. For the section of the corrugated sheet between beams, cf. Figure 7 , local buckling occurred at a force of $9.60 \mathrm{MN}$; this equals a critical stress of $1990 \mathrm{MPa}$. The analytical local buckling stress for the web of the half corrugation, cf. (21), was calculated to

$$
\sigma_{\mathrm{cr}, \text { local }}=3.6 E\left(\frac{t}{l_{b}}\right)^{2}=2140 \mathrm{MPa} .
$$

The orthotropic model does not have the same local buckling mode due to the change of geometry.
TABLe 9: Critical buckling stresses calculated for the corrugated

\begin{tabular}{|c|c|c|c|c|}
\hline & Corrugated & Orthotropic & $\begin{array}{c}\text { Half } \\
\text { corrugation }\end{array}$ & Analytical \\
\hline & FEA & FEA & FEA & beam ref. \\
\hline $\begin{array}{l}\text { 1st buckling } \\
\text { stress }(\mathrm{MPa})\end{array}$ & 1288 & $\begin{array}{c}1484 \\
\left(2101^{*}\right)\end{array}$ & 1363 & 1463 \\
\hline $\begin{array}{l}\text { Local } \\
\text { buckling } \\
\text { stress }(\mathrm{MPa})\end{array}$ & 1990 & - & 2110 & 2140 \\
\hline
\end{tabular}
sheet section situated between structural beams as described in Section 6 and Figure 7, as well as the critical stresses for a half corrugation beam, and analytically calculated references.

A summary of the critical stresses for buckling of the corrugated sheet, orthotropic model, the half corrugation, and the analytical calculations can be found in Table 9 .

\section{Discussion}

The orthotropic models suggested by Samanta and Mukhopadhyay [1] and Liew et al. [3] match the results from the modal analysis on the reference model with regard to order or modal shape. The frequencies, all except the first, also match the reference model, especially the ones calculated with the model suggested by Samanta and Mukhopadhyay, which differ with an average of 3\% from the reference model (Note: first mode not considered), cf. Table 5.

For the first eigen mode, the method presented by Briassoulis and Liew et al. gives better results than the method by Samanta and Mukhopadhyay. This mode is largely influenced by the twisting rigidity $D_{x y}$. One may conclude from this that Briassoulis expression for $D_{x y}$ is better then the expression for $D_{x y}$ presented by Samanta and Mukhopadhyay.

The modal order has changed for the model presented by Briassoulis [2] in comparison to the other models, cf. mode frequencies for type $\mathrm{d}$ and e in Table 5.

The frequency of the eigen mode type $b$, is similar for all orthotropic models because they all have similar values for $E_{x}$, see Table 4 . The difference in bending rigidities between Samanta and Briassoulis/Liew lies in the simplification: $v^{2} \approx$ 0 made by Samanta, cf. (13) and (8). 
Mode $\mathrm{d}$ is coupled to the bending rigidity $D_{y}$, Young's modulus $E_{y}$, see Figure 5(d). Here, Liew et al. [3] seem to have made improvements on Briassoulis' equation. However, the best result is given by Samanta and Mukhopadhyay's expressions [1].

The extensional moduli in $y$-direction, that is, $E_{y}^{e}$, derived by Briasssoulis and presented in Table 6, correspond well to the extensional property of the corrugated sheet in this direction, cf. the extensional benchmark results in Table 7.

The expressions for $B_{x}$ given by Briassoulis and Samanta seem to under estimate the extensional rigidity. However, Briassoulis' expressions are the better alternative, at least for this specific case.

The critical buckling stresses of the half corrugation model and the analytical calculation match each other rather well, cf. Table 9. The difference in the first critical buckling stress may be explained by the fact that the half corrugation's neutral axis actually has an inclination to the $x y$-plane. The boundary conditions applied, however, reduce the effect of twisting of the cross-section.

The orthotropic model's buckling stress is very close to that of the analytical. The corrugated model, however, has a significantly lower first buckling stress. This may be explained by two factors: the bending rigidities used in the orthotropic model showed slightly stiffer characteristics in the free vibration comparison compared to the corrugated model for the two natural modes that best fit the buckling mode, that is, mode type b and d in Figure 5, cf. Table 5, results under Samanta compared to Original. Furthermore the corrugated model cross-section shows the same effect as that of the half corrugation model, and may twist slightly to reduce the bending rigidity.

The local buckling stresses are better matched, especially for the half corrugation model and the analytical beam reference.

The buckling analysis also showed that a safety margin towards buckling of the corrugated sheets has been used in this specific construction. The first buckling mode occurred at a stress of $1288 \mathrm{MPa}$, well above the yield stress of the most common steels used for this type of construction.

\section{Conclusions}

Depending on application, the orthotropic model may be a good substitution to reduce number of elements needed in an FE model. Computational time can be reduced with an orthotropic model since the number of elements needed can be lowered below the smallest amount needed to fully model each corrugation (the entire plate may be modeled as one element; however, this would put somewhat extreme restrictions on the type of calculations, and boundary conditions that can be performed and used with accurate results).

If accurate buckling stresses are sought after, a better orthotropic model may be able to approximate the plate thickness of the orthotropic model as $t(l / c)$ instead of approximating the density as $\rho(l / c)$. However, this has implications on all bending and extensional moduli presented herein since these are derived using $t$ as the orthotropic sheet thickness. This would affect the calculations made in (6) through (7). In this study, the thickness $t$ of the orthotropic sheet was set to $1.5 \mathrm{~mm}$ in these equations.

A mix of bending rigidities from the different models could be used, that is, $D_{x}$ and $D_{y}$ from Samanta and Mukhopadhyay [1] and $D_{x y}$ from Briassoulis [2] and for the extensional rigidities the expression given by Briassoulis alone.

\section{List of Symbols}

$t: \quad$ Geometric parameter of corrugation, see Figure 1

$c: \quad$ Geometric parameter of corrugation, see Figure 1

$l$ : Geometric parameter of corrugation, see Figure 1

$d: \quad$ Geometric parameter of corrugation, see Figure 1

$f: \quad$ Geometric parameter of corrugation, see Figure 1

$\theta: \quad$ Geometric parameter of corrugation, see Figure 1

$b$ : $\quad$ Geometric parameter of corrugation, see Figure 1

$x, y, z$ : Directional coordinates, cf. Figure 1

$\sigma: \quad$ Stress component

$\epsilon: \quad$ Strain component

v: Poisson's ratio

$E$ : Young's modulus for bending

G: $\quad$ Shear modulus for bending

$D: \quad$ Bending rigidity

$E^{e}: \quad$ Young's modulus for extension and compression

$G^{e}$ : Shear modulus for extension and compression

$B$ : $\quad$ Extensional rigidity

$\alpha: \quad$ Offset contribution to the moment of inertia of half a corrugation

$\rho: \quad$ Density

I: $\quad$ Moment of inertia

A: $\quad$ Cross-section area

$P_{\text {cr: }}$ : Buckling load

$u, v, w$ : Displacements in $x, y$, and $z$, respectively.

\section{Acknowledgment}

This work is part of the project: "A Light Weight Car body for High-Speed Trains", a Ph.D. project within "Multi-functional body-panels" under the Centre for Eco ${ }^{2}$ Vehicle Design at the Royal Institute of Technology in Stockholm, Sweden, with funding from Vinnova, Bombardier Transportation, SAAB automobile, and A2Zound.

\section{References}

[1] A. Samanta and M. Mukhopadhyay, "Finite element static and dynamic analyses of folded plates," Engineering Structures, vol. 21, no. 3, pp. 277-287, 1999.

[2] D. Briassoulis, "Equivalent orthotropic properties of corrugated sheets," Computers and Structures, vol. 23, no. 2, pp. 129-138, 1986.

[3] K. Liew, L. Peng, and S. Kitipornchai, "Buckling analysis of corrugated plates using a mesh-free Galerkin method based on the first-order shear deformation theory," Computational Mechanics, vol. 38, no. 1, pp. 61-75, 2006. 
[4] HyperWorks 10, Online Help and Documentation, http://www .altairhyperworks.com/hwhelp/Altair/hw10.0/index.aspx.

[5] T. J. Easley, "Buckling formulas for corrugated metal shear diaphragms," Journal of the Structural Division, vol. 101, pp. 1403-1417, 1975.

[6] T. J. Easley and E. D. McFarland, "Buckling of light gage corrugated metal shear diaphragms," Journal of the Structural Division, vol. 95, no. 7, pp. 1497-1516, 1969.

[7] E. D. McFarland, An investigation of the static stability of corrugated rectangular loaded in pure shear, Ph.D. thesis, University of Kansas, Lawrence, Kan, USA, 1967.

[8] T. H. G. Megson, Aircraft Structures for Engineering Students, Butterworth-Heinemann, Boston, Mass, USA, 4th edition, 2007. 

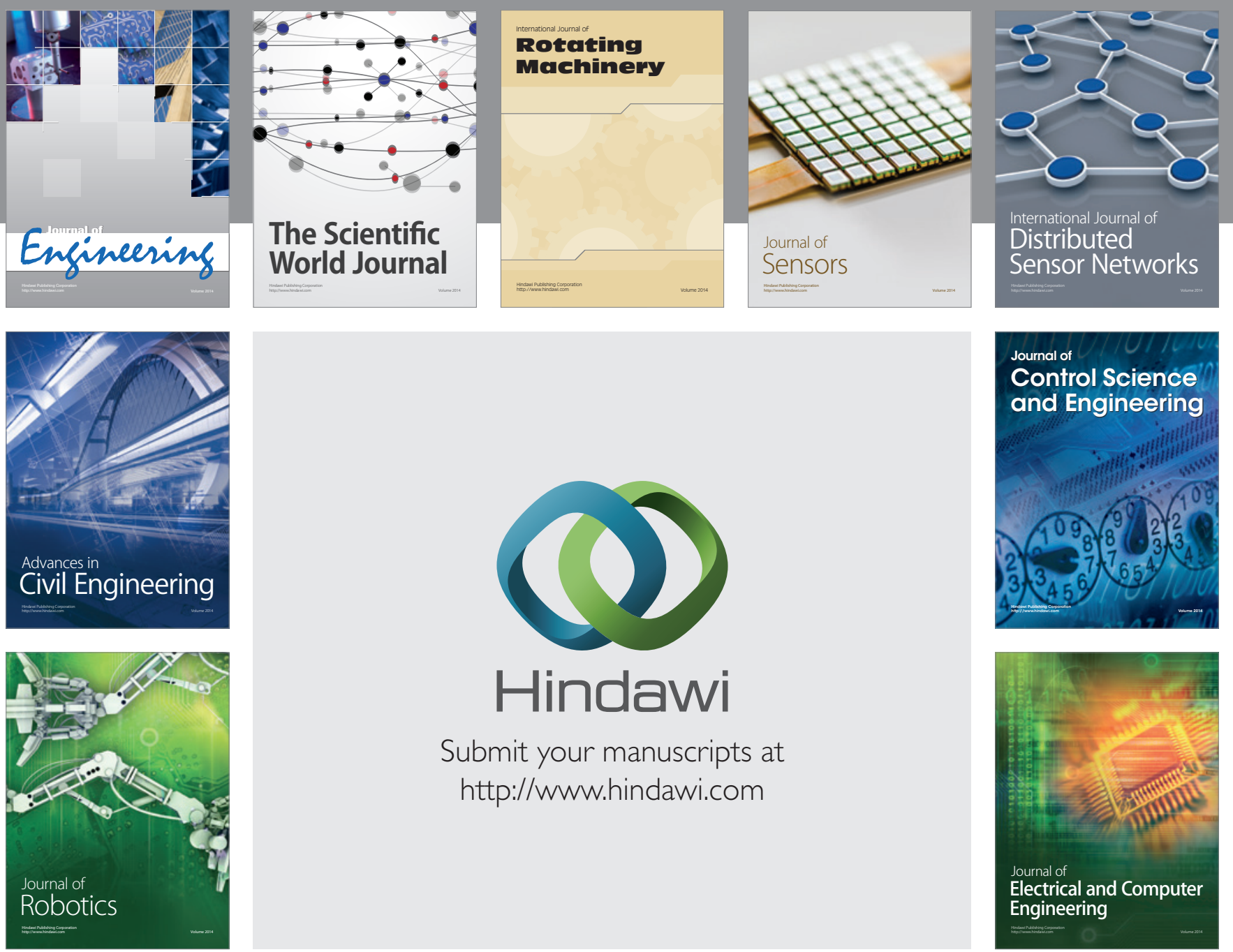

Submit your manuscripts at

http://www.hindawi.com
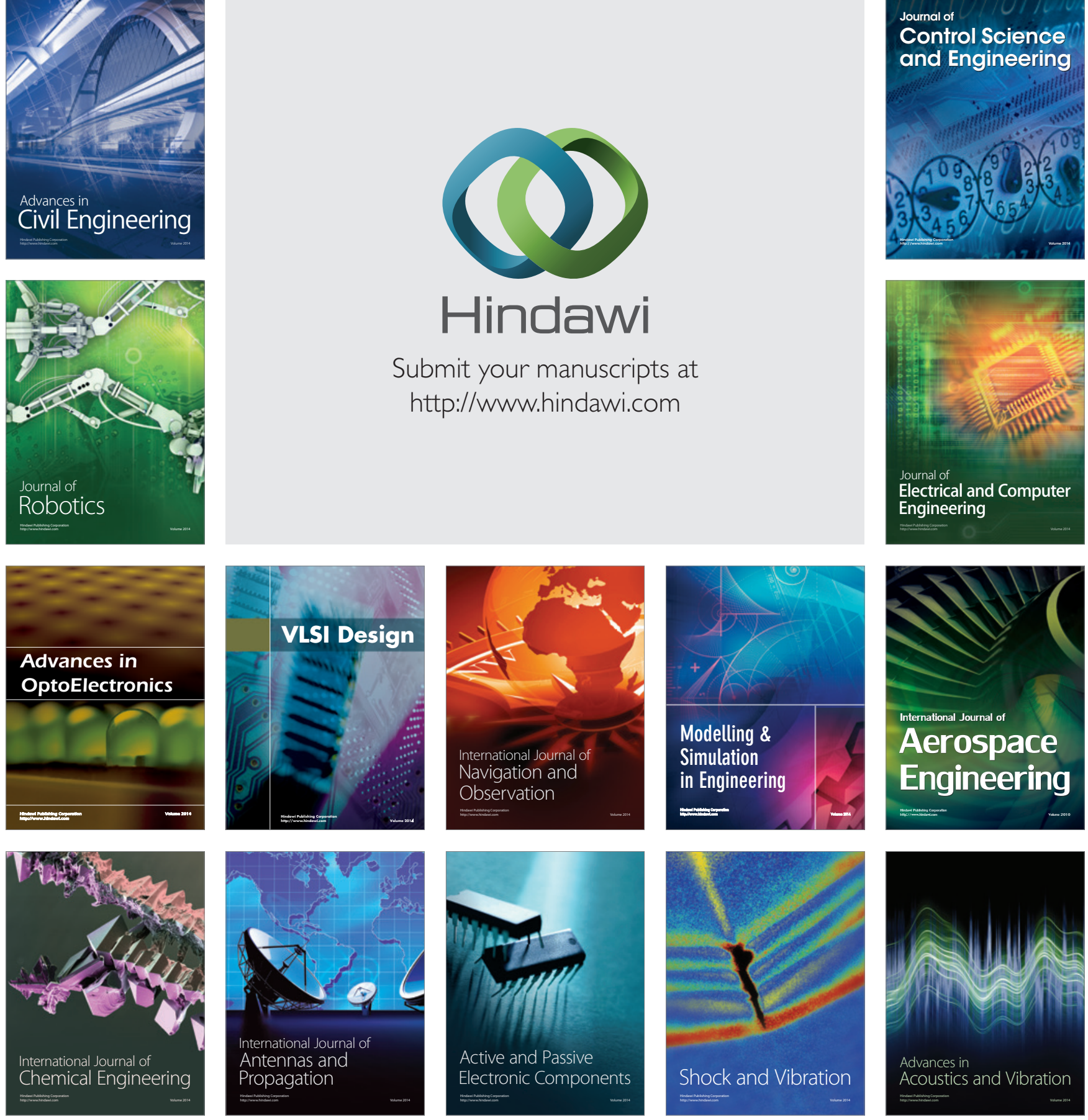